\title{
Essential role for p53-mediated transcription in E1A-induced apoptosis
}

\author{
Peter Sabbatini, ${ }^{1}$ Jiayuh Lin, ${ }^{3}$ Arnold J. Levine, ${ }^{3}$ and Eileen White ${ }^{1,2,4}$ \\ ${ }^{1}$ Center for Advanced Biotechnology and Medicine and ${ }^{2}$ Department of Biological Sciences, Rutgers University, Piscataway, \\ New Jersey 08854 USA; ${ }^{3}$ Department of Molecular Biology, Princeton University, Princeton, New Jersey 08544-1014 USA
}

\begin{abstract}
Baby rat kidney (BRK) cell lines transformed by E1A and a temperature-sensitive p53 [tsp53(val135)] undergo rapid apoptosis when p53 assumes the wild-type conformation at the permissive temperature. Wild-type p53 function is therefore required for induction of apoptosis in response to growth deregulation by E1A. BRK cells transformed by E1A and a transcriptionally defective temperature-sensitive p53 [tsp53(22-23val135)] are dramatically impaired for the ability to mediate E1A-induced apoptosis at the permissive temperature. The tsp53(22-23val135), however, still retains some ability to suppress cell growth. Thus, the activity of p53 as a transcription factor is directly correlated with the ability of E1A to induce apoptosis. In addition, there may exist at least two different mechanisms by which p53 can suppress cell-cycle progression, only one of which is dependent on p53-mediated transcription.
\end{abstract}

[Key Words: p53-Mediated transcription; apoptosis; growth suppression]

Received May 15, 1995; revised version accepted July 13, 1995.

The p53 protein is a nuclear phosphoprotein and a transcription factor capable of both trans-activating and repressing transcription (Ginsberg et al. 1991a; Farmer et al. 1992; Subler 1992; Zambetti et al. 1992). In addition, p53 can mediate either growth arrest or apoptosis, depending on the physiological circumstances (Finlay et al. 1989; Diller et al. 1990; Ginsberg et al. 1991b; YonishRouach et al. 1991; Kastan et al. 1992). The role of p53mediated transcription in the induction of growth arrest has been well documented (El-Deiry et al. 1993; Harper et al. 1993; Xiong et al. 1993). The p21/WAF-1/cip1 protein is a p53-inducible inhibitor of $\mathrm{G}_{1}$-specific cyclindependent kinases (El-Deiry et al. 1993; Harper et al. 1993; Xiong et al. 1993). The overexpression of p21/ WAF-1/cip1 in human diploid fibroblasts and mouse NIH-3T3 cells results in the inhibition of DNA synthesis (Harper et al. 1993). In addition, the overexpression of $\mathrm{p} 21 / \mathrm{WAF}-1 / \mathrm{cipl}$ in tumor cells in culture results in growth suppression (El-Deiry et al. 1993). This effect, however, is reversible, suggesting that $\mathrm{p} 21 / \mathrm{WAF}-1 / \mathrm{cip} 1$ implements the inhibition of DNA synthesis by causing cells to growth arrest (Harper et al. 1993).

The underlying mechanisms of p53-mediated apoptosis, however, are not clear. By directly interacting with the DNA repair machinery, p53 may function to delay the repair process, thus allowing lesion-induced apoptotic signals to propagate (Lane 1993; Caelles et al. 1994). Alternatively, p53 may control apoptosis by transcriptionally modulating the expression of both cell death genes and cell survival genes (Kastan et al. 1992; Lane

${ }^{4}$ Corresponding author.
1993). In this paper we demonstrate that the activity of p53 as a transcription factor is required for the induction of apoptosis by E1A in BRK cells. We also provide compelling evidence that p53-mediated transcription and growth suppression are not necessarily mutually exclusive. Therefore, $\mathrm{p} 53$-mediated growth suppression may utilize components of the cell that are distinct from those in p53-induced apoptosis.

\section{Results \\ p53-mediated transcription triggers E1A-induced apoptosis}

We have demonstrated previously that BRK cell lines expressing E1A and a temperature-sensitive p53 [tsp53(val135)] undergo p53-mediated apoptosis at the permissive temperature of $32^{\circ} \mathrm{C}$ (Debbas and White 1993; Chiou et al. 1994; Sabbatini et al. 1995). Therefore, ElA-induced apoptosis is mediated by wild-type (wt) p53. In light of the fact that p53 is a transcription factor, it was of interest to determine if p53-mediated transcription plays a pivotal role in E1A-induced apoptosis in BRK cells.

To this end, we established three independently derived BRK cell lines expressing adenovirus E1A and a transcriptionally defective murine temperature-sensitive p53 [tsp53(22-23val135)] from primary cells. Mutation of codons 22 and 23 significantly impairs p53-mediated trans-activation in part by abrogating the interaction of p53 with two subunits of the TFIID transcription complex, $\mathrm{TAF}_{\mathrm{II}} 40$ and $\mathrm{TAF}_{\mathrm{II}} 60$ (Lin et al. 1994; Thut et al. 1995). This particular mutant is also severely com- 
promised in its ability to transcriptionally repress reporter gene expression in the Saos-2 osteogenic sarcoma cell line (J.Y. Lin, S. Chen, and A.S. Levine, unpubl.). A BRK cell line expressing E1A and a transcriptionally functional murine tsp53(val135) (Michalovitz et al. 1990) was generated in parallel and was used as a control. All cell lines were established and maintained at the restrictive temperature of $38.5^{\circ} \mathrm{C}$. Western blot analysis indicated that each of the 22-23vall35 cell lines expressed both murine p53 and E1A at comparable levels and to a greater extent than that observed in the val135 control cell line (Fig. 1).

$\mathrm{p} 21 / \mathrm{WAF}-1 / \mathrm{cip} 1$ is a $\mathrm{p} 53$-inducible gene, the protein product of which inhibits $G_{1}$-specific cyclin-dependent kinases (El-Deiry et al. 1993; Harper et al. 1993; Xiong et al. 1993). Therefore, to confirm that the tsp53(2223vall35) was transcriptionally defective, we measured

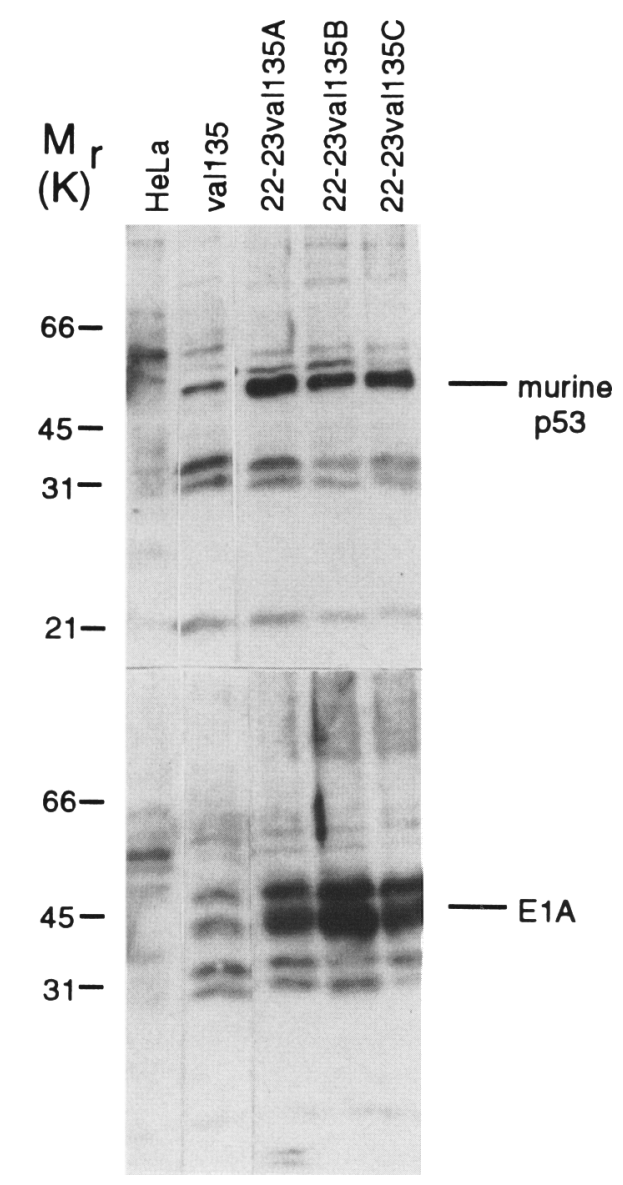

Figure 1. Expression of p53 and ElA in transformed BRK cell lines. Western blots of equal quantities of whole-cell extract from the 22-23val135A, 22-23val135B, and 22-23vall35C cell lines and the vall 35 control cell line were probed with monoclonal antibodies specific for murine p53 (top) and ElA (bottom). A HeLa cell extract was used as a negative control for the expression of $\mathrm{E} 1 \mathrm{~A}$ and $\mathrm{p} 53$, as the level of endogenous p53 in HeLa cells is barely detectable by Western blotting analysis (Benchimol et al. 1982; Debbas and White 1993; Ridgway et al. 1993). its ability to trans-activate expression of p21/WAF-1/ cipl at the permissive temperature. Cytoplasmic RNA was extracted from the vall35 and 22-23val135A cell lines at $38.5^{\circ} \mathrm{C}(0 \mathrm{hr})$ and after $4 \mathrm{hr}$ at the permissive temperature, and Northern blot analysis for expression of $\mathrm{p} 21 / \mathrm{WAF}-1 / \mathrm{cip} 1$ was subsequently performed. Expression of $\beta$-actin was used as a means of normalizing sample variation in the levels of RNA.

The temperature-dependent expression of the p53-inducible gene $\mathrm{p} 21 / \mathrm{WAF}-1 / \mathrm{cip} 1$ in the val135 control cell line confirmed that the tsp53(val135) protein was transcriptionally functional at the permissive temperature (Fig. 2). p21/WAF-1/cip1 mRNA levels in the val135 control cell line remained induced for at least $12 \mathrm{hr}$ at the permissive temperature (data not shown). In contrast, the tsp53(22-23val135) protein was transcriptionally defective at not only the restrictive but also the permissive temperature, as expression of $\mathrm{p} 21 / \mathrm{WAF}-1 / \mathrm{cip} 1$ in the 22-23val135A cell line was not induced in either circumstance (Fig. 2). p21/WAF-1/cip1 mRNA levels in the 22-23val135A cell line were also undetectable for at least $12 \mathrm{hr}$ at the permissive temperature (data not shown). In addition, p21/WAF-1 protein levels progressively increased in the val135 control cell line upon incubation at the permissive temperature, but were undetectable in the 22-23val135A cell line at both the restrictive and permissive temperatures (data not shown).

Mobility retardation analysis was performed to determine if the tsp53(22-23val135) still retained sequencespecific DNA binding at the permissive temperature. The endogenous $\mathrm{p} 53$ in the BRK cell lines, which were derived from primary BRK cells, could theoretically bind to DNA at the permissive temperature. Therefore, it may be difficult to unambiguously assess the DNA-binding ability of the tsp53(22-23val135) in the BRK cell lines. The $10(1)$ cell line, however, is an immortalized murine embryo fibroblast cell line that lacks endogenous p53 expression (Harvey and Levine 1991). To assess DNA-binding ability of the tsp53(22-23vall35) at the permissive temperature, nuclear extracts were prepared from two independently derived $10(1)$ cell lines that express only the tsp53(22-23val135) (J. Lin and A.J. Levine, in prep.). The 10(1) cell line alone and a $10(1)$ cell line that expresses the transcriptionally competent tsp53(val135) (Harvey and Levine 1991; Wu et al. 1993) were used as negative and positive controls, respectively. Nuclear extracts were prepared from cell lines that had been incubated at the permissive temperature for $6 \mathrm{hr}$. Mobility retardation studies were performed with an oligonucleotide corresponding to the p53 DNA consensus sequence and an oligonucleotide representing a scrambled p53 DNA consensus sequence as probes (Funk et al. 1992).

Results indicated that at the permissive temperature the tsp53(val135) and tsp53(22-23val135) bound to the p53 DNA consensus sequence at comparable levels (Fig. 2B). The p53 carboxyl-terminal-specific antibody 421 (Hupp et al. 1992) was able to activate only sequencespecific DNA binding (asterisk), whereas the E1A-specific antibody M73 failed to activate sequence-specific 

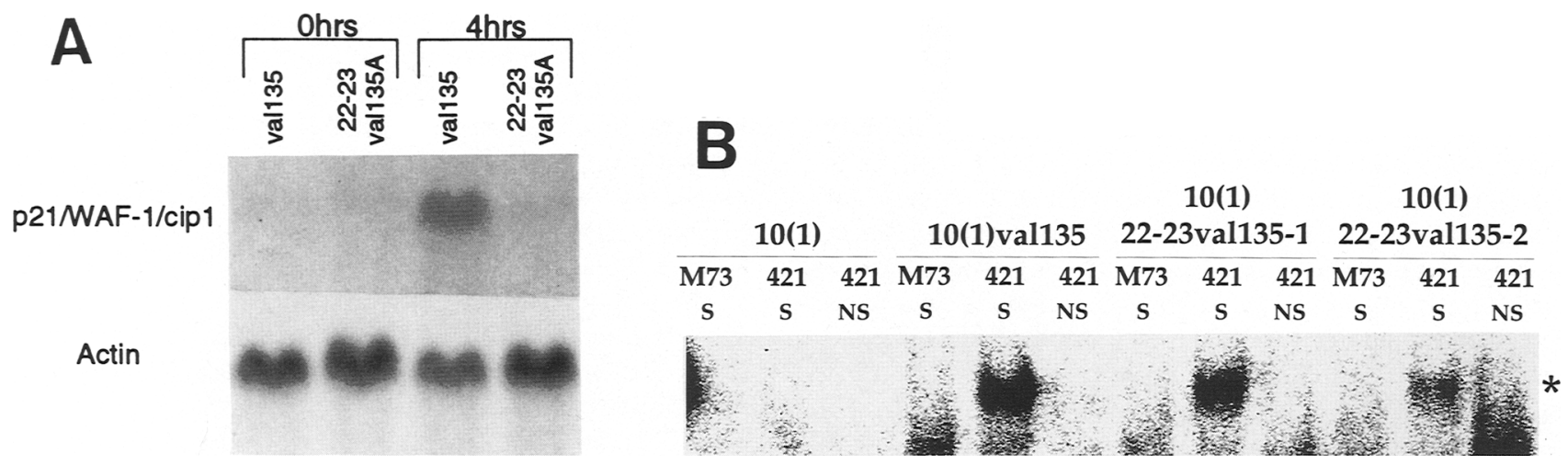

Figure 2. The 22-23val135 mutant $\mathrm{p} 53$ is defective for $p 21 / W A F-1 /$ cip1 induction but retains sequence-specific DNA binding ability. $(A)$ Northern blots of RNA isolated from the val135 and $22-23$ val135A cell lines incubated at the restrictive $(0 \mathrm{hr})$ and permissive $(4$ $\mathrm{hr}$ ) temperature were hybridized with probes corresponding to murine $\mathrm{p} 21 / \mathrm{WAF}-1 / \mathrm{cip} 1$ (top) or mouse $\beta$-actin (bottom). (B) Mobility retardation analysis of the tsp53(22-23val135) at the permissive temperature. Nuclear extracts were prepared from cell lines that had been incubating at the permissive temperature for $6 \mathrm{hr}$. Extracts were incubated in a mobility retardation reaction with a labeled p53 DNA consensus sequence (S) or nonspecific DNA sequence (NS). To activate p53 sequence-specific DNA binding, reactions were incubated with the p53 carboxy-terminal-specific antibody 421 (Hupp et al. 1992). Parallel reactions were incubated with the ElAspecific antibody M73 as a negative control. Samples were run on a $4 \%$ polyacrylamide gel at $4^{\circ} \mathrm{C}$ for $3 \mathrm{hr}$. Gels were then dried and scanned with a PhosphorImager (Molecular Dynamics).

DNA binding. Moreover, the 421 antibody was not able to activate DNA binding in nuclear extracts prepared from the $10\{1\}$ control cell line, which lacks p53 expression. In addition, immunoprecipitation of p53 from the 10(1)val135 and 10(1)22-23val135 cell lines at the permissive temperature revealed comparable levels of p53 expression. Therefore, in spite of the fact that the tsp53(22-23vall35) is transcriptionally defective, it has not lost the ability to bind to the p53 DNA consensus sequence at the permissive temperature. These same observations have been reported for the 22-23 p53 mutant in an otherwise wild-type background (Lin et al. 1994).

We assessed the viability of each 22-23vall35 cell line upon incubation at the permissive temperature to determine if the tsp53(22-23vall35) was capable of mediating E1 A-induced apoptosis. The 4P cell line was used as a control to rule out any nonspecific effects on cell proliferation that the lower permissive temperature may have on the tsp53 cell lines. The $4 \mathrm{P}$ cell line was derived from primary BRK cells transformed by adenovirus E1A and E1B (White and Cipriani 1990). It lacks a tsp53 and proliferates at both the restrictive and permissive temperatures and behaves similarly to E1A plus non-temperature-sensitive mutant p53 transformants. Cells were plated out at the restrictive temperature and $40 \mathrm{hr}$ postplating were shifted down to the permissive temperature for $1,2,3$, and 5 days. Cell viability was determined at each time point and represented as a percentage of viable cells relative to that at time 0 .

The viability of the vall 35 control cell line declined rapidly at the permissive temperature (Fig. 3A) and was accompanied by a dramatic and progressive increase in cells that had rounded up and detached from the surface (data not shown). This phenotype is characteristic of other identically constructed cell lines that undergo p53mediated apoptosis (Debbas and White 1993; Chiou et al.
1994; Sabbatini et al. 1995). In contrast, the viability of each 22-23val135 cell line remained high for 5 days subsequent to incubation at the permissive temperature (Fig. 3A). Moreover, microscopic examination of each 22-23vall35 cell line revealed no gross morphological changes and a virtual absence of apoptotic cells (data not shown).

DNA degradation into nucleosomal-sized fragments is indicative of apoptotic cell death (Wyllie 1980), and occurs upon conformational shift of tsp53(val135) from the mutant to the wild-type form in E1A plus tsp53(val135) BRK cell lines (Debbas and White 1993; Chiou et al. 1994; Sabbatini et al. 1995). Therefore, low molecular weight (Hirt) DNA was prepared from each cell line at both the restrictive and permissive temperatures to detect apoptotic DNA fragmentation.

DNA fragmentation in the characteristic nucleosome ladder pattern was dramatic in the val135 control cell line incubated for $24 \mathrm{hr}$ at the permissive temperature (Fig. 3B). A comparatively small amount of DNA degradation was evident in each of the 22-23vall35 cell lines upon incubation at the permissive temperature. This was a minor proportion of the total cell population when quantitated by Fluorescence-activated cell sorting (FACS) analysis, which monitors both live and dead cells (see Fig. 4). This small amount of cell death may reflect the contribution of transcriptionally independent mechanisms of p53-mediated apoptosis (Caelles et al. 1994), or residual transcriptional activity by the tsp53/2223val135| mutant protein or endogenous wild-type p53 protein. At this point it is difficult to ascertain which of these is the most likely possibility. Nonetheless, these results suggest a direct correlation between p53-mediated transcription and ElA-induced apoptosis in BRK cells.

Expression of murine p53 was monitored in each 22- 

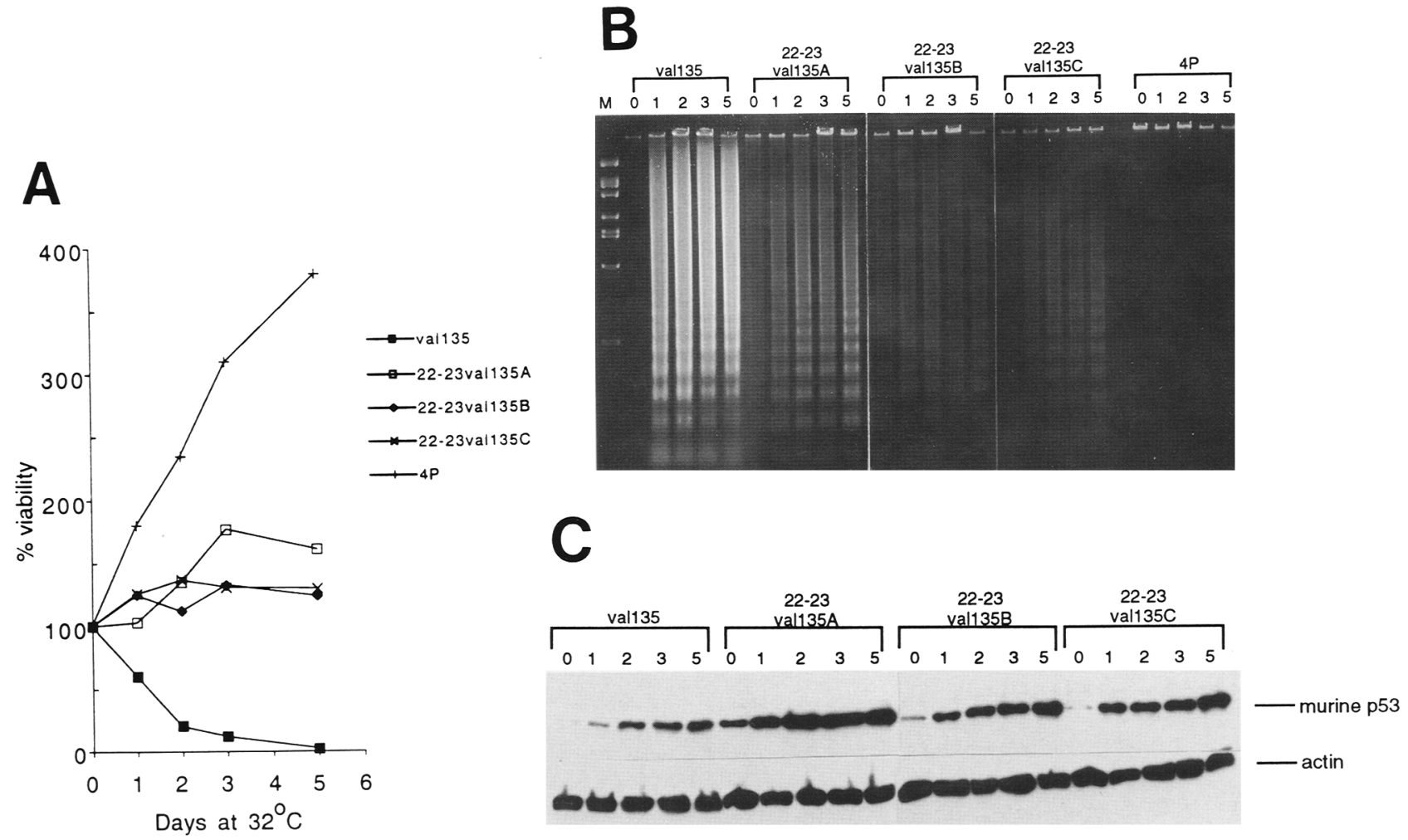

Figure 3. The tsp53(22-23val135)-expressing cell lines maintain viability at the permissive temperature. $(A)$ The viable cell number was determined for the tsp53(22-23val135)-expressing cell lines and the val135 and 4P control cell lines for 5 days at the permissive temperature by Trypan blue exclusion, and is expressed as the percentage of the original viability at the time of shift to $32^{\circ} \mathrm{C}$. $(B)$ Low molecular weight DNA was prepared and analyzed in parallel with the viability assay in Fig. 3A by use of procedures described previously (Debbas and White 1993). Ad5dl309 DNA digested with HindIII was used as a molecular weight marker (M). (C) Whole-cell extracts from viable cells only were prepared from BRK cell lines in parallel with the viability assay in $A$. Extracts were subjected to SDS-PAGE, blotted onto nitrocellulose, and probed with a monoclonal antibody specific for murine p53 (top) or actin (bottom) as described in Fig. 1.

$23 \mathrm{val} 135$ cell line to check for expression of p53 at the permissive temperature, as a lack of expression of p53 at the permissive temperature could conceivably account for the virtual absence of apoptosis. Western blot analysis indicated that the tsp53(22-23vall35) protein levels increased at the permissive temperature, as did the tsp53(val135) protein (Fig. 3C). The mechanism underlying this apparent increase in p53 protein levels has not yet been determined. In any event, the failure to undergo apoptosis at the permissive temperature was not attributable to the absence of the tsp53(22-23val135) protein.

\section{p53-mediated transcription and growth suppression} are not necessarily mutually exclusive

Although the 22-23val135 cell lines were resistant to apoptosis, cell proliferation at the permissive temperature appeared to be compromised relative to the $4 \mathrm{P}$ control cell line (Fig. 3A). These results suggested that the tsp53(22-23val135) is still capable of suppressing cell growth at the permissive temperature and that p53-mediated transcription and growth suppression are not necessarily mutually exclusive. To investigate this further, cells incubated at both the restrictive and permissive temperatures were labeled with propidium iodide and subjected to FACS analysis.

The cell-cycle profile of the $4 \mathrm{P}$ cell line growing at the restrictive temperature indicated a predominance of cells in $G_{1}$ and $S$ phase (Fig. 4). The gradual accumulation of cells in $G_{2} / M$ at the permissive temperature probably reflects a subtle decrease in the rate of cell proliferation that results from incubation at a lower temperature, as observed previously (Lin et al. 1995). The distribution of $4 \mathrm{P}$ cells throughout the cell cycle was otherwise consistent at both the restrictive and permissive temperatures. FACS analysis of the val135 cell line at the restrictive temperature indicated a predominance of cells in $G_{1}$ (Fig. 4). However, there was a progressive and dramatic increase in sub- $G_{1}$ DNA content subsequent to incubation at the permissive temperature, which is indicative of apoptotic cell death. The cell-cycle profile of the 22-23val135A cell line at the restrictive temperature indicated a predominance of cells in $\mathrm{G}_{1}$ and $S$ phase (Fig. 4). Cells also appeared to accumulate in $\mathrm{G}_{2} / \mathrm{M}$ phase upon incubation at the permissive temperature, as was seen in the $4 \mathrm{P}$ control cell line. However, in contrast to the 4P control cell line, cells of the 22- 
Sabbatini et al.

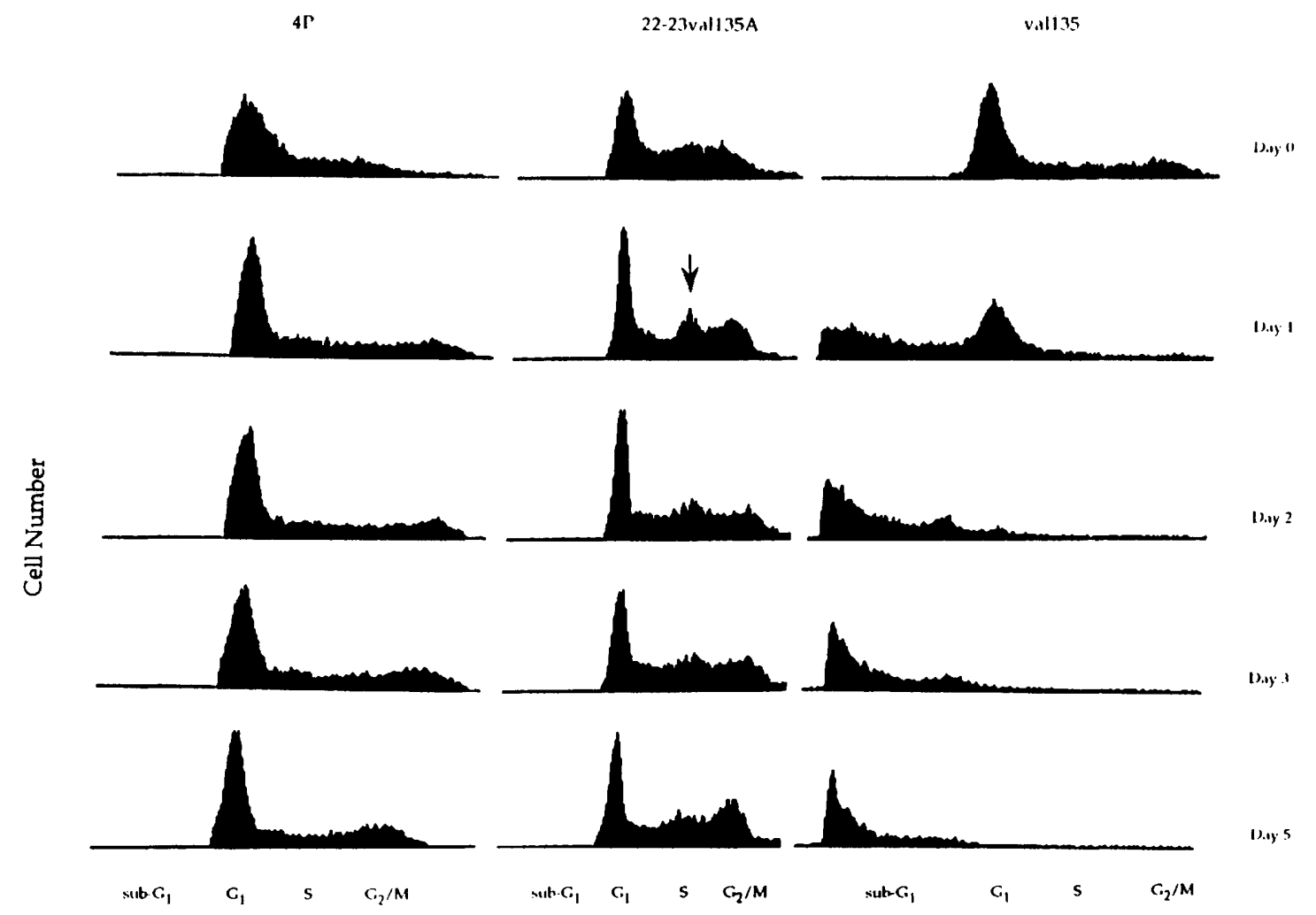

Figure 4. Cell-cycle analysis of the 22-23val135A cell line at the restrictive and permissive temperatures. $4 \mathrm{P}$ and vall35 were used as positive and negative controls, respectively, for cell growth at the permissive temperature. The $x$-axis represents relative fluorescence intensity, which is proportional to DNA content. The $y$-axis represents forward light scatter, which is proportional to cell number. The sub- $G_{1}$ DNA content is indicative of apoptotic cell death. The positions of sub- $G_{1}, G_{1}, S$, and $G_{2} / M D_{N A}$ contents are indicated.

23val135A cell line at the permissive temperature appeared to accumulate at a specific region in $S$ phase as indicated by the appearance of a distinct peak (Fig. 4). This was especially prominent at $24 \mathrm{hr}$ subsequent to incubation at the permissive temperature (arrow). There was no obvious $\mathrm{G}_{1}$ arrest at the permissive temperature with the 22-23vall35A cell line, which would be expected because of the inability to transcriptionally activate $\mathrm{p} 21 / \mathrm{WAF}-1 / \mathrm{cip} 1$. Moreover, a sub-G $\mathrm{G}_{1}$ DNA content, which increased progressively in the vall35 cell line subsequent to incubation at the permissive temperature, was absent from the 22-23val135A cell line at all time points. Therefore, in contrast to tsp53(val135), the tsp53(22-23val135) does not induce any appreciable degree of apoptosis at the permissive temperature. Instead, the tsp53(22-23val135) may be compromising cell proliferation at the permissive temperature in part by slowing progression through a specific stage or place in $\mathrm{S}$ phase without inducing complete $S$ phase arrest.

A transcriptionally defective p53 can effectively inhibit neoplastic transformation by $E 1 A$ and activated ras

Wild-type p53 has been shown to suppress transformation of primary rat embryo fibroblasts (REFs) by E1A plus activated ras (Finlay et al. 1989; Eliyahu et al. 1989). Therefore, to determine whether the transcriptional and transformation suppression functions of p53 are correlated, we measured the ability of the transcriptionally defective 22-23 p53 mutant to suppress neoplastic transformation of REFs by ElA and activated ras. Primary or secondary REFs were cotransfected with E1A, activated ras (T24), and either wild-type or mutant p53, and the number of transformed foci was determined 2-3 weeks post-transfection. The results of this experiment are presented in Table 1 as are the abilities of the individual p53 mutants to regulate transcription from a p53-responsive gene (mdm2-CAT).

The wild-type protein and two transcriptionally active p53 mutants (14-19 and 23) (Lin et al. 1994) effectively inhibited the ability of E1A and activated ras to induce neoplastic transformation (Table 1). Interestingly, the 22-23 p53 mutant was also capable of effectively suppressing transformation by E1A and activated ras. Expression of the 273 p53 mutant, which is defective for both DNA binding and p53-mediated transcription (Lin et al. 1994), did not significantly inhibit E1A and activated ras-induced transformation (Table 1). Thus, p53mediated transcription may contribute to suppression of neoplastic transformation, but another function of $\mathrm{p} 53$ is also sufficient. 
Table 1. The effect of mutant or wild-type human $p 53$ on the transformation of REFs by ras plus E1A

\begin{tabular}{lcccc}
\hline & \multicolumn{3}{c}{ Number of foci/dish } & \multicolumn{2}{c}{$\begin{array}{c}\text { Percent CAT activity } \\
\text { relative to wild-type p53 }\end{array}$} \\
\cline { 2 - 4 } Transfected DNA & exp. 1 & exp. 2 & average & 49 \\
ras + E1A & 50 & 48 & 44 & 100 \\
ras + E1A + vector & 44 & 43 & 4 & 41 \\
ras + E1A + wild-type p53 & 4 & 3 & 1 & 74 \\
ras + E1A + 14-19 & 1 & 0 & 4 & 8 \\
ras + E1A + 23 & 6 & 1 & 7 & 6 \\
ras + E1A + 22-23 & 5 & 8 & 24 & \\
ras + E1A + 273 & 24 & 23 & & \\
\hline
\end{tabular}

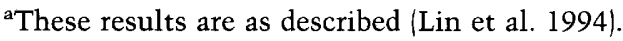

\section{Discussion}

p53-mediated transcription plays a pivotal role in E1A-induced apoptosis in BRK cells

We have demonstrated in this report that BRK cell lines expressing E1A and a transcriptionally functional tsp53/val135) undergo rapid apoptosis at the permissive temperature, whereas those expressing E1A and a transcriptionally defective tsp53(22-23val135) do not. Instead, cell viability remains relatively constant over prolonged incubation at the permissive temperature with a virtual absence of apoptotic cells. Moreover, the virtual absence of apoptotic cells in the 22-23vall 35 cell lines at the permissive temperature was not attributable to any concomitant decreases in the levels of expression of the p53 protein.

These results lend insight to the controversial role of p53-mediated transcription in the induction of apoptosis (Kastan et al. 1992; Raff 1992; Lane 1993; Caelles et al. 1994). p53-mediated apoptosis is correlated with decreases in the expression of $\mathrm{Bcl}-2$ and increases in the expression of Bax, a cellular antagonist of Bcl-2 (Miyashita et al. 1994). In fact, recent evidence indicates that p53 is a direct transcriptional activator of the bax gene (Miyashita and Reed 1995). In addition, the overexpression of Bcl-2 or the adenovirus Bcl-2 analog, E1B 19K, has been shown to rescue BRK cells from p53-mediated apoptosis (Debbas and White 1993; Chiou et al. 1994; Sabbatini et al. 1995). Therefore, p53-mediated apoptosis in certain cell types may result from either the trans-activation of cell death genes or the transcriptional repression of cell survival factors. This is entirely consistent with the fact that the tsp53(22-23val135) is defective for both transactivation (Lin et al. 1994) and transcriptional repression (J.Y. Lin, J. Chen, and A.J. Levine, unpubl.).

Analysis of small molecular weight DNA from the tsp53(22-23val135)-expressing BRK cell lines incubated at the permissive temperature did reveal some degree of DNA degradation (Fig. 3B), although cell death was insignificant when both live and dead cells were monitored by FACS analysis (Fig. 4). This is probably not the result of endogenous p53 transcriptional activity as the 2223 vall 135 is constitutively overexpressed and a dominant-negative mutant at both the restrictive and permissive temperatures. This is evidenced by the lack of trans- activation of $\mathrm{p} 21$ /WAF-1 in the 22-23val135A cell line at both temperatures (Fig. 2). It may be that the tsp53/2223val135/ possesses residual transcriptional activity at the permissive temperature, and that this, in turn, is sufficient to trigger a small degree of apoptosis but not enough to compromise overall cell viability. This explanation would still be consistent with p53-mediated transcription being directly correlated with E1A-induced apoptosis. Alternatively, p53 may be capable of mediating apoptosis through transcriptionally independent mechanisms (Caelles et al. 1994). In this respect, Haupt et al. (this issue) have demonstrated that the transcriptionally defective 22-23 p53 mutant can induce apoptosis in HeLa cells. This suggests that p53 may mediate apoptosis in certain cell types primarily through transcriptionally independent mechanisms. HeLa cells, for example, already express the cell-death promoter Bax and thus may be primed to undergo apoptosis, which could occur by transcriptionally independent means (i.e. destruction of a survival factor). BRK cells do not express Bax (P. Sabbatini and E. White, unpubl.), and Bax induction by p53 may be required for apoptosis in BRK cells. Thus, p53 may possess two mechanisms for stimulating apoptosis, destruction of a survival factor or activation of a death factor, either of which may be sufficient to induce apoptosis. The particular pathway utilized may depend on cell type or the physiological state of the cell.

\section{p53-mediated growth suppression can occur independently of p53-mediated transcription}

$\mathrm{G}_{1}$-specific growth arrest by $\mathrm{p} 53$ is thought to result in all or in part from the trans-activation of $p 21 /$ WAF-1/cip1, the protein product of which inhibits $\mathrm{G}_{1}$ specific cyclin-dependent kinases (El-Deiry et al. 1993; Harper et al. 1993; Xiong et al. 1993). Therefore, $G_{1}$ specific growth arrest by p53 is likely to be transcriptionally dependent. Expression of the tsp53(val135) in the murine fibroblast cell line (10) 1 induces $G_{1}$-specific growth arrest at the permissive temperature (Michalovitz et al. 1990; Martinez et al. 1991; Wu and Levine 1994). (10)1 cells that express the tsp53(22-23val135), however, do not undergo $G_{1}$-specific growth arrest at the permissive temperature and, instead, display a pattern of cell-cycle progression that is similar to that of the paren- 
tal (10) 1 cell line at the permissive temperature (J. Lin and A.J. Levine, unpubl.). The tsp53(22-23vall35) did retain some ability to suppress cell growth in BRK cells at the permissive temperature (Fig. 4). This appeared to be the result of cells slowing down or pausing in $S$ phase rather than cells undergoing complete $S$ phase arrest. Therefore, $\mathrm{G}_{1}$-specific growth arrest by p 53 may be transcriptionally dependent, but p53 is also capable of suppressing cell growth at other stages of the cell cycle through a transcriptionally independent mechanism. The ability of p53 to bind to and inhibit the function of the cellular DNA replication factor, RPA, could be one mechanism by which p53 functions to suppress cell growth in BRK cells independently of transcription ( $\mathrm{Li}$ and Botchan 1993; Dutta et al. 1994). This has interesting implications in light of the fact that BRK cells that express E1A and the tsp53(22-23val135) accumulate to a certain extent in $\mathrm{S}$ phase upon downshift to the permissive temperature (Fig. 4).

The concept of a transcriptionally defective p53 having growth suppressing capabilities is not without precedence. There is evidence that p53 may suppress E7-mediated transformation of primary REFs through a transcriptionally independent mechanism /Crook et al. 1994). In addition, a p53 lacking its trans-activation domain can partially suppress transformation of REFs by ElA and activated ras (Unger et al. 1993). Our results demonstrating the ability of the $22-23$ p 53 mutant to suppress transformation of REFs by E1A and activated ras are entirely consistent with these findings. Moreover, the fact that the 22-23 mutant suppresses cell growth of BRK cells independently of apoptosis suggests that $\mathrm{p} 53$ is capable of suppressing E1A and ras-mediated transformation by transcriptionally dependent and independent mechanisms. The observation that p53-mediated transcription and growth suppression are not necessarily mutually exclusive brings new insight into the role of p53 as a transcription factor and tumor suppressor.

\section{Materials and methods}

Plasmids and establishment of cell lines

BRK cells were transfected with plasmids pCMVElA (White et al. 1991), and either pmsvcgvall35neo or pmsvcg22-23val135neo (Lin et al. 1994). The pmsvcgval 135 neo plasmid encodes for the murine tsp53(val135), which is in the mutant conformation at the restrictive temperature of $38.5^{\circ} \mathrm{C}$ and the wild-type conformation at the permissive temperature of $32^{\circ} \mathrm{C}$ (Michalovitz et al. 1990). The pmsvcg22-23val135neo plasmid is identical to pmsvcgval135neo with the exception that there is a double mutation at codons 22 and 23 (which corresponds to codons 25 and 26 of murine p53) within the trans-activation domain of $\mathrm{p} 53$. The corresponding protein is designated tsp53(22-23val135) and is significantly impaired for both p53-mediated transactivation (Lin et al. 1994; Thut et al. 1995) and transcriptional repression (J.Y. Lin, S. Chen, and A.J. Levine, unpubl.).

Transfections of primary BRK cells with plasmid DNA and establishment of transformed cell lines were as described previously (Debbas and White 1993). Cell lines were screened by Southern blot analysis, and three independently derived cell lines were chosen for further characterization. The three cell lines expressing E1A and tsp53(22-23val135) were designated 22-23vall35A, 22-23vall35B, and 22-23val135C, whereas the val135 cell line expressed E1A and tsp53(val135). All cell lines were maintained at $38.5^{\circ} \mathrm{C}$ in Dulbecco's modified Eagle medium (DMEM) with 10\% fetal bovine serum.

The p53 null cell line $10(1)$ and the $10(1)$ val135 cell line, which expresses the murine tsp53(val135), have been described (Harvey and Levine 1991; Wu et al. 1993). The 10(1)22-23val135 cell lines constitutively express the murine tsp53(22-23val135) (J. Lin and A. J. Levine, in prep.). These cell lines were also maintained at $38.5^{\circ} \mathrm{C}$ in DMEM with $10 \%$ fetal bovine serum.

\section{Antibodies and Western blotting}

The monoclonal antibody 248 directed against murine p53 was used as described previously (Debbas and White 1993). The monoclonal antibody M73 directed against ElA was purchased from Oncogene Science (Uniondale, NY).

Cell extracts for Western blot analysis were prepared from subconfluent cultures, and $20 \mu \mathrm{g}$ of protein from each cell line was analyzed by SDS-PAGE and semi-dry blotting onto nitrocellulose membranes by standard procedures. Immune complexes were detected by enhanced chemiluminescence (ECL) according to the manufacturer's specifications (Amersham).

\section{Northern blot analysis}

Cytoplasmic RNA was extracted from the val135 and 22$23 v a l 135 \mathrm{~A}$ cell lines at $38.5^{\circ} \mathrm{C}(0 \mathrm{hr})$ and after $4 \mathrm{hr}$ at the permissive temperature with methods described previously (White et al. 1986; Sabbatini et al. 1995). Cytoplasmic RNA (10 $\mu \mathrm{g})$ from each cell line was analyzed by Northern blotting as described (Sabbatini et al. 1995). The probes used for Northern blot analysis were a cDNA corresponding to mouse p21/WAF-1/ cipl (generously provided by G. Hannon, Cold Spring Harbor Laboratory, Cold Spring Harbor, NY) and a cDNA corresponding to mouse $\beta$-actin (generously provided by B. Antoni, University of Medicine and Dentistry of New Jersey, Piscataway).

\section{Gel electrophoretic mobility-retardation assay}

Nuclear extracts were prepared and mobility retardation reactions were performed as described previously (Bayle et al. 1995). The oligonucleotide probes representing the p53 consensus and non-consensus sequences were 5'-AGCTTAGGCATGTCTAGGCATGTCTA-3' and $5^{\prime}$-TATGTCTAAGGGACCTGCGGTTGGCATTGATCTTG-3', respectively (Funk et al. 1992). To activate sequence-specific DNA binding of $\mathrm{p} 53,1 \mu \mathrm{g}$ of antibody 421 (Oncogene Science, Uniondale, NY) was added at the beginning of the mobility retardation reaction. Parallel reactions were incubated with $1 \mu \mathrm{g}$ of the E1A-specific antibody M73 as a negative control. Samples were loaded onto a $4 \%$ polyacrylamide gel containing $0.25 \times \mathrm{TBE}$ and electrophoresed at $4^{\circ} \mathrm{C}, 300$ $\mathrm{V}$ for $3 \mathrm{hr}$. Gels were then dried and scanned with a PhosphorImager (Molecular Dynamics).

\section{Viability and DNA fragmentation analysis}

Cells were plated out at $10^{6}$ cells per $10-\mathrm{cm}$ plate at $38.5^{\circ} \mathrm{C}$. Forty hours postplating, plates were shifted to $32^{\circ} \mathrm{C}$ and cell viability was determined at $1,2,3$, and 5 days by Trypan blue exclusion. 4P was used as a positive control for viability at $32^{\circ} \mathrm{C}$ (White and Cipriani 1990). The viable number of cells at each time point is represented as a percentage of viable cells relative to that at time 0 . Low molecular weight DNA was prepared and 
analyzed in parallel with the viability assay using procedures described previously (Hirt 1967). Samples were normalized by loading low molecular weight DNA prepared from an equal number of cells.

\section{FACS analysis}

Cells were propagated at $38.5^{\circ} \mathrm{C}$ or were shifted to $32^{\circ} \mathrm{C}$ and cultured for $1,2,3$, and 5 days as indicated. Cells were then harvested, fixed, and stained with propidium iodide using methods described previously (Kastan et al. 1991). Fluoresence intensities were determined by quantitative flow cytometry, and profiles were generated on a FACSCAN profile analyzer (Becton Dickinson).

\section{REF transformation assay}

REFs were maintained at $37^{\circ} \mathrm{C}$ in DMEM with $10 \%$ fetal bovine serum. Primary REFs were prepared from 14- to 15-day-old Fisher 344 rat embryos. Primary or secondary REFs were cotransfected with $1.5 \mu \mathrm{g}$ of an activated ras (T24), $1.5 \mu \mathrm{g}$ of $\mathrm{E} 1 \mathrm{~A}$, and either $5 \mu \mathrm{g}$ of wtp53, mutant $\mathrm{p} 53$, or vector alone, and $12 \mu \mathrm{g}$ of salmon sperm DNA by standard calcium phosphate precipitation. As a positive control, REFs were transfected with $1.5 \mu \mathrm{g}$ of activated ras (T24), $1.5 \mu \mathrm{g}$ of E1A plus $17 \mu \mathrm{g}$ of salmon sperm DNA. Transformed foci were counted 2-3 weeks posttransfection. Experiments were performed in duplicate.

\section{Acknowledgments}

We thank G. Hannon for the mouse p21/WAF-1/cipl plasmid (pBS SK-.mp21), and B. Antoni for the mouse $\beta$-actin plasmid (pBSMBA). This work was supported by grants from the National Institutes of Health (CA53370 and CA60088) to E.W.

The publication costs of this article were defrayed in part by payment of page charges. This article must therefore be hereby marked "advertisement" in accordance with 18 USC section 1734 solely to indicate this fact.

\section{References}

Bayle, J.H., B. Elenbaas, and A.J. Levine. 1995. The carboxylterminal domain of the p53 protein regulates sequence-specific DNA binding through its nonspecific nucleic acid-binding activity. Proc. Natl. Acad. Sci. 92: 5729-5733.

Benchimol, S., D. Pim, and L. Crawford. 1982. Radioimmunoassay of the cellular protein p53 in mouse and human cell lines. EMBO J. 1: 1055-1062.

Caelles, C.A., A. Heimberg, and M. Karin. 1994. p53-dependent apoptosis in the absence of transcriptional activation of p53target genes. Nature 370: 220-223.

Chiou, S.-K., L. Rao, and E. White. 1994. Bcl-2 blocks p53-dependent apoptosis. Mol. Cell. Biol. 14: 2556-2563.

Crook, T., N.J. Marston, E.A. Sara, and K.V. Vousden. 1994. Transcriptional activation by p53 correlates with suppression of growth but not transformation. Cell 79: 817-827.

Debbas, M. and E. White. 1993. Wild-type p53 mediates apoptosis by E1A which is inhibited by E1B. Genes \& Dev. 7: 546-554.

Diller, L., J. Kassel, C.E. Nelson, M.A. Gryka, G. Litwak, M. Geghardt, and B. Bressac. 1990. p53 functions as a cell cycle control protein in osteosarcomas. Mol. Cell. Biol. 10: 5772 5781 .

Dutta, A., J.M. Ruppert, J.C. Aster, and E. Winchester. 1994. Inhibition of DNA replication factor RPA by $\mathrm{p} 53$. Nature
365: 79-82.

El-Deiry, W.S., T. Tokino, V.E. Velculescu, D.B. Levy, R. Parsons, J.M. Trent, D. Lin, E. Mercer, K.W. Kinzler, and B. Vogelstein. 1993. WAF1, a potential mediator of p53 tumor suppression. Cell 75: 817-825.

Eliyahu, D., D. Michalovitz, S. Eliyahu, O. Pinhasi-Kimhi, and M. Oren. 1989. Wild-type p53 can inhibit oncogene-mediated focus formation. Proc. Natl. Acad. Sci. 86: 8763-8767.

Farmer, G., J. Bargonetti, H. Zhu, P. Friedman, R. Prywes, and C. Prives. 1992. Wild-type p53 activates transcription in vitro. Nature 358: 83-86.

Finlay, C.A., P.W. Hinds, and A.J. Levine. 1989. The p53 protooncogene can act as a suppressor of transformation. Cell 57: 1083-1093.

Funk, W.D., D.T. Pak, R.H. Karas, W.E. Wright, and J.W. Shay. 1992. A transcriptionally active DNA-binding site for human p53 protein complexes. Mol. Cell. Biol. 12: 2866-2871.

Ginsberg, D., F. Mechta, M. Yaniv, and M. Oren. 1991a. Wildtype p53 can down-modulate the activity of various promoters. Proc. Natl. Acad. Sci. 88: 9979-9983.

Ginsberg, D., D. Michael-Michalovitz, D. Ginsberg, and M. Oren. 1991b. Induction of growth arrest by a temperaturesensitive p53 mutant is correlated with increased nuclear localization and decreased stability of the protein. Mol. Cell. Biol. 11: 582-585.

Harper, J.W., G.R. Adami, N. Wei, K. Keyomarsi, and S.J. Elledge. 1993. The p21 cdk-interacting protein cipl is a potent inhibitor of G1 cyclin-dependent kinases. Cell 75: 805816.

Harvey, D.M. and A.J. Levine. 1991. p53 alteration is a common event in the sppontaneous immortalization of primary BALB/c murine embryo fibroblasts. Genes \& Dev. 5: 23752385.

Haupt, Y., S. Rowan, E. Shaulian, K. Vousden, and M. Oren. 1995. Induction of aptosis in HeLa cells by trans-activationdeficient p53. Genes \& Dev. (this issue).

Hupp, T.R., D.W. Meek, C.A. Midgely, and D.P. Lane. 1992. Regulation of the specific DNA binding function of p53. Cell 71: 875-886.

Hirt, B. 1967. Selective extraction of polyoma DNA from infected mouse cultures. J. Mol. Biol. 26: 365-369.

Kastan, M.B., O. Onyekwere, D. Sidransky, B. Vogelstein, and R.W. Craig. 1991. Participation of p53 protein in the cellular response to DNA damage. Cancer Res. 51: 6304-6311.

Kastan, M.B., Q. Zhan, W.S. El-Deiry, F. Carrier, T. Jacks, W.V. Walsh, B.S. Plunkett, B. Vogelstein, and A.J. Fornace. 1992. A mammalian cell cycle checkpoint pathway utilizing p53 and GADD45 is defective in ataxia-telangiectasia. Cell 13: 587 597.

Lane, D.P. 1993. A death in the life of p53. Nature 362: 786-787.

$\mathrm{Li}, \mathrm{R}$. and R. Botchan 1993. The acidic transcriptional activation domains of VP16 and p53 bind the cellular replication protein A and stimulate in vitro BPV-1 DNA replication. Cell 73: 1207-1221.

Lin, J., J. Chen, B. Elenbaas, and A.J. Levine. 1994. Several hydrophobic amino acids in the p53 amino-terminal domain are required for transcriptional activation, binding to $\mathrm{mdm}-2$ and the adenovirus $5 \mathrm{E} 1 \mathrm{~B} 55-\mathrm{kD}$ protein. Genes \& Dev. 8: 1235-1246.

Lin, H.-J.L., V. Eviner, G. Pendergrass, and E. White. 1995. Activated $\mathrm{H}$-ras rescues E1 A-induced apoptosis and cooperates with E1A to overcome p53-dependent growth arrest. Mol. Cell. Biol. 15: 4536-4544.

Martinez, J., I. Georgoff, J. Martinez, and A.J. Levine. 1991. Cellular localization and cell cycle regulation by a temperaturesensitive p53 protein. Genes \& Dev. 5: 151-159. 
Michalovitz, D., O. Halevy, and M. Oren. 1990. Conditional inhibition of transformation and of cell proliferation by a temperature-sensitive mutant of p53. Cell 62: 671-681.

Miyashita, T. and J.C. Reed. 1995. Tumor suppressor p53 is a direct transcriptional activator of the human bax gene. Cell 80: 293-299.

Miyashita, T., S. Krajewski, M. Krajewska, H.G. Wang, H.K. Lin, D.A. Liebermann, B. Hoffman, and J.C. Reed. 1994. Tumor suppressor p53 is a regulator of bcl-2 and bax gene expression in vitro and in vivo. Oncogene 9: 1799-1805.

Raff, M.C. 1992. Social controls on cell survival and cell death. Nature 356: 398-400.

Ridgway, P.J., T.K. Hale, and A.W. Braithwaite. 1993. p53 confers a selective advantage on transfected HeLa cells. Oncogene 8: 1069-1074.

Sabbatini, P., S.-K. Chiou, L. Rao, and E. White. 1995. Modulation of p53-mediated transcriptional repression and apoptosis by the adenovirus ElB $19 \mathrm{~K}$ protein. Mol. Cell. Biol. 15: $1060-1070$.

Subler, M.A., D.W. Martin, and S. Deb. 1992. Inhibition of viral and cellular promoters by human wild-type p53. J. Virol. 66: 4757-4762.

Thut, C.J., J.-L. Chen, R. Klemm, and R. Tjian. 1995. p53 transcriptional activation mediated by coactivators $\mathrm{TAF}_{1 \mathrm{I}} 40$ and TAF $_{\text {II }} 60$. Science 267: 100-104.

Unger, T., J.A. Mietz, M. Scheffner, C.L. Yee, and P.M. Howley. 1993. Functional domains of wild-type and mutant p53 proteins involved in transcriptional regulation, transdominant inhibition, and transformation suppression. Mol. Cell. Biol. 13: $5186-5194$.

White, E. and R. Cipriani. 1990. Role of adenovirus E1B proteins in transformation: Altered organization of intermediate filaments in transformed cells that express the 19-kilodalton protein. Mol. Cell. Biol. 10: 120-130.

White, E., R. Cipriani, P. Sabbatini, and A. Denton. 1991. The adenovirus E1B 19-kilodalton protein overcomes the cytotoxicity of ElA proteins. J. Virol. 65: 2968-2978.

White, E., B. Faha, and B. Stillman. 1986. Regulation of adenovirus gene expression in human WI-38 cells by an E1B-encoded tumor antigen. Mol. Cell. Biol. 6: 3763-3773.

$\mathrm{Wu}, \mathrm{X}$. and A.J. Levine. 1994, p53 and E2F-1 cooperate to mediate apoptosis. Proc. Natl. Acad. Sci. 91: 3602-3606.

Wu, X., J.H. Bayle, D. Olson, and A.J. Levine. 1993. The p53mdm-2 autoregulatory feedback loop. Genes \& Dev. 7: 1126-1132.

Wyllie, A.H. 1980. Cell death: The significance of apoptosis. Int. Rev. Cytol. 68: 251-306.

Xiong, Y., G. Hannon, H. Zhang, D. Casso, R. Kobayashi, and D. Beach. 1993. p21 is a universal inhibitor of cyclin kinases. Nature 366: 701-704.

Yonish-Rouach, E., D. Resnitzky, J. Lotem, L. Sachs, A. Kimchi, and M. Oren. 1991. Wild-type p53 induces apoptosis of myeloid leukaemic cells that is inhibited by interleukin-6. $\mathrm{Na}$ ture 352: 345-347.

Zambetti, G.P., J. Baronetti, K. Walker, C. Prives, and A.J. Levine. 1992. Wild-type p53 mediates positive regulation of gene expression through a specific DNA sequence element. Genes \& Dev. 6: 1143-1152. 


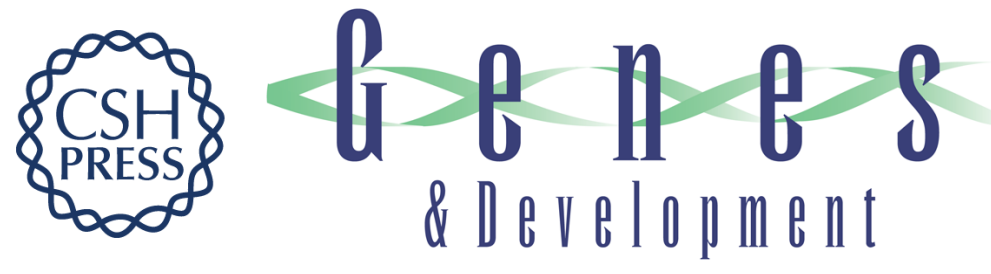

\section{Essential role for p53-mediated transcription in E1A-induced apoptosis.}

P Sabbatini, J Lin, A J Levine, et al.

Genes Dev. 1995, 9:

Access the most recent version at doi:10.1101/gad.9.17.2184

References This article cites 44 articles, 23 of which can be accessed free at:

http://genesdev.cshlp.org/content/9/17/2184.full.html\#ref-list-1

License

Email Alerting Receive free email alerts when new articles cite this article - sign up in the box at the top Service right corner of the article or click here.

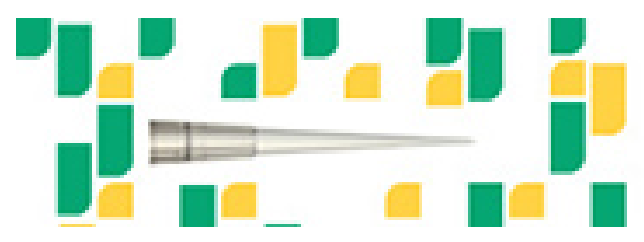

Focused on your science.

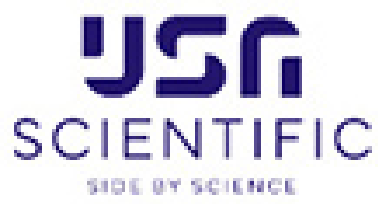

Copyright @ Cold Spring Harbor Laboratory Press 